\title{
O MERCOSUL E A CRISE: \\ A INTEGRAÇÃO DA AMÉRICA DO SUL E O APARENTE PARADOXO EUROPEU
}

\author{
THE MERCOSUR AND THE CRISIS: THE SOUTH AMERICAN \\ INTEGRATION AND THE EUROPEAN APARENT PARADOX
}

\begin{abstract}
Cristiane $\mathrm{Cabral}^{1}$
Alex Ian Psarski Cabral ${ }^{2}$

SUMÁRIO: Introdução. $1 \mathrm{O}$ conceito de integração: supranacionalidade e intergovernamentalidade. 2 Breves considerações sobre o modelo europeu e a integração na América do Sul. 2.1 A integração europeia. 2.2 Breve histórico da integração na América do Sul. 2.3 Espeque institucional e fragilidades do Mercosul. 2.4 A nova soberania como limite à integração? Conclusão - O resgate da vocação integracionista dos Estados da América do Sul. Referências.

RESUMO: O presente trabalho tem o intuito de analisar, sob o enfoque da integração econômica, os efeitos das crises americana e europeia para o processo de integração na América do Sul e Latina, especialmente, o Mercosul. Inobstante a crise quem tem atravessado, o projeto europeu ainda pode considerado como paradigma significativo de integração. Por outro lado, o projeto da América do Sul core deste trabalho impõe que se analise a construção sulamericana, suas instituições e desafios para esse novo contexto mundial. É preciso refletir-se sobre o impacto do individualismo Estatal e as possibilidades do incremento das relações de cooperação entre os povos.

Palavras-chave: Mercosul. Integração. União Europeia. Crise.

ABSTRACT: This work aims to analyze, under the focus of economic integration, the effects of the American and European crisis to the integration process on South and Latin American, especially Mercosur. Beyond the crisis, the European project can still be considered as the paradigm of integration. On the other hand, the South America project, basis on this paper, requires the analysis of South American construction, its institutions and the challenges on this new global context. It is important to reflect about the impact of the State's individualism and the possibilities of increasing the relationship of cooperation among commonwealth.
\end{abstract}

Keywords: Mercosur. Integration. European Union. Crisis.

\section{INTRODUÇÃO}

Diante de tantas mudanças globais - recentemente a crise nos EUA e na Europa, além da instabilidade no mundo Árabe - nunca foi tão necessário discutir o aprofundamento das relações de cooperação no projeto de integração dos Estados da América do Sul e América Latina.

A situação econômica dos vizinhos do Norte repete em muito a crise do ano de 2008 e a diferença é que, dessa vez, o enredo contempla um novo e relevante personagem: o Velho Mundo. Enquanto os Estados Unidos cogitam rever estratégias no seu sistema financeiro, a Europa amarga o seu próprio drama, arrastando consigo países como Portugal, Grécia, Espanha e até a Itália.

\footnotetext{
${ }^{1}$ Mestre em Ciências Jurídico-Internacionais pela Faculdade de Direito - Universidade de Lisboa. Doutoranda em Direito Internacional Pública pela PUC/MG. Possui interesse nas áreas de Direito Constitucional e Internacional.

${ }^{2}$ Doutorando em Direito Público Internacional pela Pontifícia Universidade Católica de Minas Gerais (PUC-MG). Mestre em Ciências Jurídico-Internacionais pela Faculdade de Direito da Universidade de Lisboa, Portugal. Especialista em Direito do Estado. Professor universitário e da Academia de Polícia Militar do Estado de Minas Gerais. Pesquisador Coordenador do Grupo de Estudos Sobre Tratados Internacionais Assinados Pelo Brasil no Centro de Direito Internacional (CEDIN). Pesquisador CNPQ do Grupo de Pesquisas "Investigação Científica Constituição e Processo" pela Pontifícia Universidade Católica de Minas Gerais (PUC-MG). Pesquisador CNPQ do Grupo de Pesquisas "Desafios da Integração na América Latina e Caribe" pela Universidade Católica de Minas Gerais (PUC-MG).
} 
Esses episódios não devem ofuscar o rompante de democracia vivido nos últimos meses pelo Mundo Árabe. Inaugurados pela Tunísia e favorecidos pelas redes sociais da internet, os movimentos populares disseminaram-se por países como Egito, Líbia e Síria, exigindo respeito à liberdade e profundas reformas sociais contra a tendência repressora das teocracias absolutistas que há décadas perpetuam-se no poder.

Desde o século XIX, outros dois fenômenos proporcionaram profundas transformações nas relações internacionais, com repercussão direta sob a organização interna dos Estados. A globalização e a diminuição das fronteiras entre os Estados, e posteriormente, a abertura das economias possibilitou a formação de compartimentos regionais de integração, os denominados blocos econômicos.

Há algum tempo, a tendência para o regionalismo acentuou-se, na sequência dos processos de descolonização, resultando na elaboração de projetos de integração política e econômica para os Estados. Grandes potências, especificamente europeias, foram as primeiras a despertar para a necessidade de se preparar para os desafios da regionalização, recorrendo ao aprofundamento dos laços de cooperação como tática defensiva ${ }^{3}$.

É aí que reside o grande paradoxo. Embora pioneira e visionária, a Europa integracionista não foi capaz de evitar a crise de 2011. Ao contrário, após a disseminação dos efeitos da crise, a União Europeia passou a conviver com a antiga sombra da desconfiança dos mais céticos em relação à chamada Zona do Euro.

Como consequência, velhos questionamentos ressoaram impondo novos desafios à comunidade internacional. Até que ponto a Europa pode servir de paradigma para modelos integracionistas neonatos como o MERCOSUL? A integração, até então tida como um grande trunfo europeu, ainda pode ser considerada uma alternativa confiável para os Estados da América do Sul?

Antes de pormenorizarmos a questão da integração, esboçando suas consequências e aferindo suas potencialidades para o futuro, cumpre aqui registrar alguns conceitos relevantes a esse respeito.

\section{O CONCEITO DE INTEGRAÇÃO: SUPRANACIONALIDADE E INTERGOVERNAMENTALIDADE}

Inicialmente, destacam-se dois conceitos distintos: integração e cooperação - enquanto a cooperação tem natureza econômico-social, o fenômeno da integração pressupõe índole político-econômica.

Na distinção de Balassa (BALASSA, 1961), ao tempo em que a integração pressupõe um amplo entendimento entre os Estados, pretendendo-se a supressão completa de formas de discriminação entre os envolvidos, a cooperação tem objetivos menos ambiciosos, satisfazendo-se com a mera redução dessas diferenças em torno da consecução de objetivos específicos mais restritos.

A integração pressupõe etapas de um processo contínuo e global, tal como ocorreu na gênese das comunidades europeias, sua construção e respectivos alargamentos, culminando na União Europeia. Daí afirmar-se que o regionalismo internacional está relacionado, ao mesmo tempo, a conceitos políticos, econômicos e jurídicos.

Do ponto de vista jurídico, destaca-se uma função internacional geral que consiste em favorecer as instituições regionais e reforçar o corpus das normas regionais, evitando-se os mecanismos universais e a adoção de regras de alcance geral.

\footnotetext{
${ }^{3}$ Cf. DINH; DAILLIER; PELLET, 1999.
} 
A integração política é decorrente de uma afinidade preexistente no campo econômico ${ }^{4}$, nomeadamente nas trocas comerciais entre os Estados ${ }^{5}$. Ou seja, embora a proposta da integração se construa pelo viés econômico, a iniciativa econômica não é mais que um instrumento a favor da integração, orientado, nesse sentido, por decisões de caráter político-econômico.

Além disso, para a realização dos objetivos pretendidos pelos Estados participantes do processo, é imprescindível que haja também uma integração no âmbito normativo. O dogma da segurança jurídica impõe a criação de uma ordem jurídica comum e harmoniosa, respeitada por todos os Estados integrantes ${ }^{6}$.

Contudo, não é exagero concluir-se que o procedimento de integração econômica tangencia a integração política ${ }^{7}$, ainda que para isso se valha de um complexo regime jurídico e econômico. A integração política aqui é, ao mesmo tempo, o método e o objetivo, o fim e o meio.

Nas relações internacionais, os Estados podem alinhar-se conforme um modelo intergovernamental ou supranacional de integração, a depender de uma série de fatores que variam conforme a percepção preponderante de soberania entre eles.

Segundo o Professor Fausto de Quadros (QUADROS, 1997, p. 50):

os europeus sempre se convenceram, mesmo os britânicos - estes mais tarde - de que a integração só seria possível num quadro de limitação da soberania dos Estados". Segundo ele, "foi e é uma opção consciente. Fracassou o projeto de mundialização ou globalização da Comunidade Internacional (...).

A ordem supranacional se reflete na legislação derivada, emanada dos órgãos comunitários, bem como na própria aplicação das normas jurídicas, sujeitas a um Tribunal de Justiça, cujos julgados se impõem aos Estados membros.

\footnotetext{
4 "Do ponto de vista econômico a integração internacional é um instrumento - e não um fim - ao serviço de interesses econômicos nacionais dos países participantes. Aliás, sempre a análise é feita em relação aos efeitos produzidos sobre as economias nacionais por comparação com a situação anterior à integração. Integram-se as economias com vista a melhorar a eficiência da sua estrutura produtiva e comercial (...)" (FERREIRA, 1997, p. 30).

5 Segundo Mendonça Pinto, "a integração monetária surge, de fato, como consequência lógica e inevitável do aprofundamento da integração nos domínios comercial, produtivo e financeiro, assim como também será um potente mecanismo de convergência das políticas econômicas e de aproximação dos comportamentos sociais nos vários Estados-membros, originando, a prazo, uma maior integração política". De certo modo, continua ele, pode dizer-se que no processo da União Monetária, para além dos argumentos econômicos, há também uma intenção política de manter a Europa no caminho da integração. Tal como uma bicicleta só se mantém em equilíbrio se estiver em andamento, assim também a integração monetária parece ser agora a força necessária para fazer avançar a UE, vindo a propósito citar Jacques Rueff, o economista conselheiro do general De Gaulle, que em tempos escreveu: "A Europa far-se-á pela moeda, ou não se fará" (PINTO, 1995, p. 50-52).

${ }^{6}$ Cite-se como exemplo, o Título VI do Tratado de Maastrich, referente à Cooperação policial y judicial em matéria penal, em substituição ao antigo Título VI do Tratado de Maastrich, entitulado "Cooperação nos assuntos de Justiça e Internos". Desde o ponto de vista material, a maior parte do conteúdo dos assuntos de justiça e internos foram ali comunitarizados passando a constituir objeto do Título IV do TCE. Esse comunitarização encontrou uma grande resistência nas matérias de cooperação policial e judicial penal, por sua evidente vinculação especial ao exercício da coerção, próprio do núcleo duro da soberania estatal (NOGUERAS; MARTÍN, 2002, p. 60).

7 Foram sempre objetivos de natureza política que determinaram decisivamente os processos de integração. Assim sucedeu na Europa, quer com as CEs, quer com a EFTA. Nas outras experiências de integração as razões políticas foram também as determinantes (tendo estado, posteriormente, também na origem do seu relativo fracasso). Nas mais recentes evoluções da integração econômica internacional as razões políticas não estão afastadas e relacionam-se diretamente com o fenômeno de polarização que as relações econômicas internacionais assumem atualmente (FERREIRA, 1997, p. 30).
} 
Segundo Fausto de Quadros (QUADROS, 2004), uma concepção comunitária das relações entre os Estados e entre os indivíduos visa criar entre esses Estados uma margem tão ampla quanto possível de solidariedade, impondo a criação de um poder integrado, de relações verticais de subordinação entre esse poder, por um lado, e os Estados e seus sujeitos internos, por outro, com base em um Direito Comum.

A chamada "supranacionalidade", definida como ordem das soberanias subordinadas normativamente, tem lastro, segundo ele (FAUSTO, 2004, p. 100), na "superioridade hierárquica do poder supranacional sobre o poder estadual". Desafia o conceito clássico de soberania e impõe uma série de medidas no sentido de regulamentar esse poder supranacional.

A supranacionalidade implica, portanto, numa cessão da soberania dos Estados em favor de uma organização dotada de capacidade decisória e de participação plena em toda a conjuntura do processo de integração.

É marcada pelo Modelo Comunitário ${ }^{8}$, dotado de bases com estrutura vertical, cujos Estados têm a soberania limitada. É esse limite que assegura o poder de integração, dando substância ao poder comunitário ou supranacional ${ }^{9}$.

Vale dizer, apesar das evidentes diferenças perante o modelo intergovernamental, no sistema supranacional as revisões dos tratados constitutivos são feitas via conferências intergovernamentais, e a sua aprovação depende da assinatura de todos os Estados Membros, para a consequente entrada em vigor.

Ao contrário da supranacionalidade, o modelo intergovernamental implica no absoluto respeito à soberania clássica. Por conta disso, os Estados estão em primeiro plano e são dotados de amplos poderes de decisão, conforme o interesse individual de cada um deles e não da organização de um modo geral.

As organizações intergovernamentais seguem o Modelo Societário ou de Cooperação, que, como o próprio nome sugere, propõe a cooperação de soberanias nacionais.

Está inserido no contexto da comunidade internacional clássica, sob a égide do respeito à soberania desses Estados. É, portanto, a afirmação do individualismo de cada um deles, que se sobrepõe aos interesses comuns ${ }^{10}$.

O modelo intergovernamental é formado por órgãos deliberativos, compostos por representantes dos Estados e estão diretamente subordinados a eles.

As decisões não possuem efeito direto nos Estados, nem se sobressaem perante o direito interno, mas devem respeitar o critério da unanimidade e refletir a concordância de todos os Estados, nesse sentido, para serem efetivamente aplicadas, devem antes submeter-se ao processo constitucional de internalização.

Essas linhas conceituais são relevantes para necessária distinção entre projetos mais avançados de integração como a União Europeia e aqueles que ainda almejam ultrapassar a etapa da cooperação, a exemplo do Mercosul.

\footnotetext{
${ }^{8}$ Não se deve confundir a dicotomia existente entre modelo comunitário e modelo societário (ou de cooperação) com outra não menos importante, existente entre método comunitário e método intergovernamental. O método comunitário, situado no plano comunitário, relaciona-se com aspectos da supranacionalidade, enquanto que o método intergovernamental, baseando-se na idêntica dignidade e capacidade de decisão, estrutura a intergovernamentalidade. 2005, p. 70 .

9 O Direito Comunitário, vale dizer, nasce sob esse contexto, vinculando os Estados Membros. E, no âmbito interno de cada um desses Estados, são as pessoas físicas ou jurídicas que se vinculam diretamente, uma vez que esse direito deve primar sobre o direito nacional. O modelo comunitário atualmente só é alcançado pela União Europeia.

${ }^{10}$ No modelo de cooperação que caracteriza o sistema intergovernamental, não há nenhum poder superior aos Estados, havendo uma "relação horizontal de coordenação de soberanias".
} 


\section{BREVES CONSIDERAÇÕES SOBRE O MODELO EUROPEU E A INTEGRAÇÃO NA AMÉRICA DO SUL}

\subsection{A integração europeia}

A pujante estrutura institucional da União Econômica e Monetária Europeia traduz um projeto voluntariamente sistematizado, produto da trajetória histórica das relações interestatais no continente europeu.

A vocação integracionista da Europa remonta ao período situado entre a Idade Média e o Renascimento, marcado, no plano político, pela afirmação da soberania dos Estados, no plano religioso, pela Reforma e, no plano econômico, pelo crescimento das rivalidades econômicas inerentes ao nacionalismo. (QUADROS, 2004, p. 32)

O primeiro grande passo para a história da Europa comunitária foi dado pelo projeto Schumman, em maio de $1950^{11}$. Propondo acordo econômico de cooperação mútua entre França e Alemanha, traduziu a primeira etapa daquela que seria a Federação Europeia, rompendo com os paradigmas regionais de produção de armas de guerra $^{12}$.

Mais tarde, com a adesão da França, Alemanha, Itália, Bélgica, Holanda e Luxemburgo, teria como consequência a criação da Comunidade Europeia do Carvão e do Aço (CECA) em 18 de Abril de 1951, pelo Tratado de Paris ${ }^{13}$.

O conceito de União Europeia como uma União Econômica e Monetária surge no ano de 1975, como consequência de um parecer elaborado pelo então primeiro ministro belga, por ocasião da Cimeira de Paris ocorrida no ano anterior. Léo Tindemans é considerado também um dos precursores da ideia de cidadania europeia.

Passados nada menos que sessenta anos desde então, a União Europeia experimentou sucessivos alargamentos e diversos tratados ${ }^{14}$ - incluindo do Ato Único Europeu, que entrou em vigor no dia $1^{\text {o }}$ de julho de 1987 - até o mais recente documento, assinado em Lisboa em dezembro de 2007.

Atualmente, a União Europeia conta com um sofisticado quadro institucional. Para atender aos princípios democráticos, o processo de tomada de decisões funciona conforme um complexo esquema de atribuições e competências

\footnotetext{
11 Inspirado nos ideais de Jean Monnet, o projeto foi de autoria do então Ministro dos Negócios Estrangeiros da França, Robert Schuman, propunha a instituição de uma autoridade comum, dotada de decisões com poder vinculativo, para exercer a regulamentação dos dois maiores meios econômicos da época: o carvão e o aço.

12 “A proposta de criação de uma federação europeia também não trazia consigo o rasgo da inovação. Há mais de um século, a unidade europeia era pensada e oferecida sob diferentes modelos organizatórios, com particularidade de quase todos eles reproduzirem o paradigma federal. Na verdade, o genuíno toque de inspiração do Plano Schuman reside no método proposto - é o chamado método de integração funcionalista" (DUARTE, 2001. p 40).

${ }^{13}$ Entrando em vigor em 25 de Julho de 1952, "o Tratado de Paris foi a concretização da primeira organização comunitária a surgir das cinzas da Segunda Guerra Mundial, num contexto de reconstrução econômica e processo de pacificação do continente europeu. (...) Com vistas à criação do mercado comum, o Tratado instaurou a liberdade de circulação dos produtos, sem direitos aduaneiros nem encargos". . 2005, p. 334.

${ }^{14} \mathrm{O}$ próprio Tratado de Paris, que constituiu a Comunidade Europeia do Carvão e do Aço (CECA) assinado em 18 de Abril de 1951; o Tratado de Roma, assinado em 25 de Março de 1957, que deu origem à Comunidade Econômica Europeia (CEE) e à Comunidade Européia de Energia Atômica (EURATOM); o Tratado instituidor da União Europeia (TUE), assinado em 07 de Fevereiro de 1992, em Maastrich, na Holanda; o Tratado de Amsterdã, assinado em 02 de Outubro de 1997; o Tratado de Nice, assinado em 26 de Fevereiro de 2001; o Tratado Constitucional, que chegou a ser adotado pelo consenso de cento e cinco membros, no dia 13 de junho de 2003, mas não prosperou; entre outros documentos.
} 
envolvendo quatro instituições fundamentais: o Conselho Europeu, o Conselho de Ministros, a Comissão Europeia e o Parlamento Europeu.

Além dessa base institucional fundamental, há ainda o Tribunal de Justiça, com atribuição de garantir o cumprimento da legislação europeia; o Tribunal de Contas, que fiscaliza o financiamento das atividades da União; o Comitê Econômico e Social, representativo da sociedade civil, empregados e empregadores, o Banco Central Europeu, responsável pela política monetária, além outros muitos órgãos e agências com funções específicas nos quadros da União Europeia.

Inobstante a crise quem tem atravessado, o projeto europeu ainda pode ser considerado como paradigma significativo de integração. Por outro lado, o projeto da América do Sul, core deste trabalho, impõe que se analise a construção sul-americana, suas instituições e desafios para esse novo contexto mundial.

\subsection{Breve histórico da integração na América do Sul}

A trajetória de integração na América do Sul inicia-se com os projetos de aliança e união política na América Meridional no século XVIII, e segue com as ideias de integração na América Latina até desembocar na integração dos Estados do Eixo Sul.

O venezuelano Francisco Miranda é considerado precursor na ideia de uma união americana no século XVIII. Em 1791, o plano de criar um único grande país, desde o Mississipi até a Patagônia, foi entregue ao Primeiro Ministro da Grã Bretanha, William Pitt ${ }^{15}$.

Em seguida, as "Declaraciones del Pueblo de Chile" aludia à necessidade de uma união através da criação de um Congresso, tudo com o intuito defender a soberania dos povos da América Latina. Considerada "a primeira união do sul" consistiu, na verdade, num primeiro acordo de amizade e comércio firmado entre a Junta de Buenos Aires, Argentina e o Chile, em 21 de março de 1811.

Em 1822, Simón Bolívar, presidente de "La Gran Colombia" - união da Colômbia, Venezuela e Equador - propôs a criação de uma confederação perpétua, convidando os governos do México, Peru, Chile e Buenos Aires (Argentina) ${ }^{16}$.

Já no século XX, no final da Década de 50, a Comissão Econômica para a América Latina e Caribe (CEPAL) lançou as primeiras ideias integracionistas na região a partir do diagnóstico acerca da necessidade de industrialização da América Latina, baseado num processo de substituição de importações.

O propósito de integração econômica na América Latina foi inaugurado com a constituição da Associação Latino-Americana de Livre Comércio (ALALC). Resultou fundamentalmente dos trabalhos da CEPAL, realizados por governos de Argentina, Brasil, Chile e Uruguai. Refletia um pouco de preocupação com a criação da Comunidade Econômica Europeia em 1957, através do Tratado de Roma ${ }^{17}$.

O Tratado da ALALC baseou-se no permissivo do artigo XXIV do GATT (Acordo Geral Sobre Tarifas Aduaneiras e Comércio, em inglês "General Agreement On Tariffs and Services"). O dispositivo autorizava as partes contratantes a estabelecer livremente uniões aduaneiras ou zonas de livre comércio entre si.

\footnotetext{
15 “Miranda deseaba crear un único gran país, desde Mississipi a La Patagonia y propuso esta Idea a William Pitt, primer ministro de Gran Bretaña, com La salvedad de que tal unificación no fuera en contra del principio sacorsanto de la división internacional del trabajo" (ARNAUD, 1999, p. 43).

${ }^{16}$ Inspirado no "Ensayo sobre una Confederación Continental" de Bernardo de Monteagudo, Bolívar convidou Estados Unidos, Argentina, Brasil e Chile para um Congresso a realizar-se em 1826, no Panamá. (SILVA, 1946, p. 15 e ARNAUD, 1999, p. 45).

${ }^{17}$ Foi inicialmente subscrito por Argentina, Brasil, Chile, México, Paraguai, Peru e Uruguai. Em seguida, aderiram Colômbia, Equador, Venezuela e Bolívia.
} 
A ALALC tem antecedente na conferência intergovernamental de 1959, culminando no Tratado de Montevidéu - cujos efeitos durariam até o final dos anos 70 constituindo a primeira tentativa de criação de uma Zona de Comércio Livre na América Latina.

Além de uma Zona de Livre Comércio, a ALALC previa a criação de um Mercado Comum Latino-americano, conforme disposto no art. 54 do Tratado de Montevidéu. Criava mecanismos periódicos de negociação - as listas nacionais - com as concessões de cada país à Zona - e as listas comuns, enumerando os produtos livres de barreiras alfandegárias (ARNAUD, 1999, p. 45).

Inicialmente, estipulava um prazo de doze anos a partir da data da sua criação, conforme o art. $2^{\circ}$ do Tratado da ALALC. Mas o prazo logo foi ampliado para vinte anos, através de protocolo assinado em Caracas em 12 de dezembro de 1970.

Todavia, não obteve o mesmo êxito de sua congênere europeia, a associação Europeia de Livre Comércio (EFTA), esbarrou na ausência de vontade política e nas próprias dificuldades das economias latino-americanas, e teve que ser substituída.

Vinte anos depois da ALALC, em 12 de agosto de 1980, Argentina, Bolívia, Brasil, Chile, Colômbia, Cuba, Equador, México, Paraguai, Peru, Uruguai e Venezuela ${ }^{18}$ firmaram o $2^{\circ}$ Tratado de Montevidéu, criando a Associação LatinoAmericana de Integração (ALADI)

A ALADI propôs uma rede de convergência de alcance parcial através de três mecanismos: a) Preferência Tarifária Regional (PAR, art. $5^{\circ}$ ), b) Acordos de Alcance Regional (AAR, arts. $6^{\circ}$ e 18); c) Acordos de Alcance Parcial (AAP - arts. $7^{\circ}$ a 14 e 19 a 23 ).

Além disso, também permitiu que países membros firmassem acordos com outras nações latino-americanas ou em desenvolvimento.

Sem dúvida, o grande mérito da ALADI foi criar um sistema institucional flexível, que reconhece a heterogeneidade da região e cujas regras integracionistas não ousaram com metas quantitativas preestabelecidas.

O tratamento diferenciado entre países com desenvolvimento médio, maior ou menor, dava prosseguimento a um processo de integração a "longo prazo", com o intuito de estabelecer "de forma gradual e progressiva" um "mercado comum latinoamericano" (ARNAUD, 1999, p. 125).

Foi diante do permissivo da ALADI sobre o estabelecimento de acordos bilaterais que Argentina e Brasil firmaram, em 1986, o Programa de Integração Comercial e Econômica (PICE), substituído de fato em 1991, pelo Tratado de Assunção, que deu origem ao MERCOSUL.

Juridicamente, o MERCOSUL é o resultado do encontro de vontades da República Argentina, da República Federativa do Brasil, da República do Paraguai e da República Oriental do Uruguai que, aos 26 dias do mês de março do ano de 1991, assinaram o Tratado de Assunção, com vistas à criação do Mercado Comum do Sul.

O objetivo primordial do Tratado de Assunção é a integração dos Estados Partes através da livre circulação de bens, serviços e fatores produtivos, do estabelecimento de uma Tarifa Externa Comum (TEC), da adoção de uma política comercial comum, da coordenação de políticas macroeconômicas e setoriais, e da harmonização de legislações nas áreas pertinentes.

Situado dentro da integração latino-americana, o acordo intentava expressamente a formação de um mercado comum. Todavia, na concretização de tais

\footnotetext{
${ }^{18}$ Os Estados que compõem a ALADI são os mesmos que uma dia foram parte da ALALC. Cuba, que tinha status de observador desde 1986, ingressou na ALADI em 6 de novembro de 1986 (ARNAUD, 1999. p.125).
} 
objetivos, o acordo esteve sempre esbarrando nas divergências internas dos Estados Membros, mormente no que tange aos aspectos institucionais.

Após o Tratado de Assunção, reuniram-se, em dezembro de 1994, na Cúpula de Ouro Preto, os Presidentes dos Estados Partes do MERCOSUL. Naquele momento foi aprovado o Protocolo Adicional ao Tratado de Assunção - o Protocolo de Ouro Preto - com o fito de estabelecer a estrutura institucional do MERCOSUL e consagrar a sua personalidade jurídica internacional ${ }^{19}$.

Ao mesmo tempo em que o MERCOSUL dava os primeiros passos, Peru, Equador, Colômbia, Chile ${ }^{20}$ e Bolívia (e, em fevereiro de 1973, a Venezuela ${ }^{21}$ ) também avançavam rumo à integração. A Comunidade Andina das Nações (CAN - Comunidad Andina de las Naciones) nasceu em 26 de maio de 1969, em decorrência do Pacto Andino, estabelecido a partir da assinatura do Acordo de Cartagena ${ }^{22}$.

A CAN tem por objetivo o desenvolvimento uniforme, equilibrado e harmonioso dos países membros com a consequente redução das diferenças de desenvolvimento existentes entre eles ${ }^{23}$.

Além da óbvia influência do ideal integracionista de Simón Bolívar, a CAN foi motivada pela insatisfação de alguns participantes da ALALC, principalmente países médios e pequenos, alegando haver disparidade nos benefícios daquele Tratado.

Desde o dia $1^{\circ}$ de fevereiro de 1995, com a implantação da Tarifa Externa Comum, a Zona de Livre Comércio formada por Bolívia, Colômbia, Equador, Venezuela e Peru constitui-se como uma União Aduaneira incompleta.

Sua estrutura institucional aproxima-se mais do modelo comunitário europeu do que do modelo intergovernamental. Prova disso, em 1984 entrou em vigor o Tratado de Constituição do Tribunal de Justiça da Comunidade Andina, com competência para controlar a legalidade das normas comunitárias.

A mais recente iniciativa de integração da América do Sul deu-se em 8 de dezembro do ano de 2004, com a assinatura da Declaração de Cuzco.

Inspirados nos mesmo ideais de Simón Bolívar, chefes de Estado e de Governo de doze países da América do Sul - Argentina, Bolívia, Brasil, Colômbia, Chile, Equador, Guiana, Paraguai, Peru, Suriname, Uruguai e Venezuela - decidiram lançar mão de um novo espaço regional de integração política, social, econômica e ambiental.

O tratado constitutivo da União de Nações Sul-Americanas (UNASUL) foi aprovado em maio de 2008 em Brasília, durante reunião extraordinária de chefes de Estado e de governo.

Cercada de entusiasmo e contando com o otimismo dos integracionistas, a UNASUL persegue a convergência entre o Mercosul e a Comunidade Andina e o Chile,

\footnotetext{
${ }^{19}$ Em Ouro Preto, concluiu-se o período de transição, adotando-se os instrumentos fundamentais de política comercial comum que caracterizam a União Aduaneira.

${ }^{20}$ Tendo se retirado em 1976/1977, o Chile tornou-se mero observador passando a membro associado à CAN. Em 24 de novembro de 2006 foi assinada a "Ata de Constituição da Comissão Mista entre a Comunidade Andina e o Chile", considerado o primeiro passo para o retorno do país ao bloco.

${ }^{21}$ Em 22 de Abril de 2006, a Venezuela denunciou os acordos do bloco retirando-se da CAN para integrar oficialmente o MERCOSUL. Maiores informações em: 〈https://www.comunidadandina.org >. Acesso em 06 de maio de 2013.

${ }^{22} \mathrm{O}$ Acordo constitui o ordenamento jurídico da Comunidade Andina, justamente com os seus Protocolos e instrumentos adicionais, demais Tratados com seus Protocolos modificadores; as Decisões do Conselho Andino de Relações Exteriores e da Comissão da Comunidade Andina; as Resoluções da Secretaria Geral da Comunidade Andina, os Convênios de Complementação Industrial, entre outros.

${ }^{23}$ A integração econômica e social pretende a aceleração do crescimento e do nível de emprego, visando a formação gradual de um mercado comum latino-americano, ampliando a participação dos países membros no ambiente internacional. Nesse sentido, OCAMPO, 2009, p. 368.
} 
através do aperfeiçoamento da Zona de Livre Comércio, na esteira da Resolução 59 do XIII Conselho de Ministros da ALADI, de 18 de outubro de 2004.

Em 30 de setembro de 2005, na Reunião de Brasília, a UNASUL estabeleceu como ações prioritárias o diálogo político, a integração física, o meio ambiente, a integração energética, os mecanismos financeiros, as assimetrias, a promoção da coesão, da inclusão e da justiça social e as telecomunicações.

A UNASUL pretende aproveitar-se das experiências bilaterais, regionais e sub-regionais existentes para avançar nas etapas da integração econômica, social e institucional. A União inclui ainda a harmonização de políticas de desenvolvimento, a cooperação tecnológica e os investimentos de infra-estrutura física para região.

Contudo, apesar do mau momento vivenciado pelo Velho Mundo, é de se reconhecer que a União Europeia ainda constitui a iniciativa mais bem sucedida em matéria de integração.

Enquanto isso, em estágios bem menos avançados, Mercosul e UNASUL engatinham institucionalmente. As "nouvelles" trazidas à UNASUL e principalmente a estrutura institucional do MERCOSUL mostram-se ainda insuficientes, num sistema acanhado e, ainda, inacabado de cooperação.

\subsection{Espeque institucional e fragilidades do MERCOSUL}

Com arquitetura extremamente simples e estrutura minimalista, o Mercosul ainda está em processo de aperfeiçoamento. Além dos problemas referentes ao seu sistema organizacional, o processo de decisão adota o critério do consenso dos Estados Partes, o que impede maiores avanços no bloco.

A estrutura básica do Mercosul é composta pela Secretaria Técnica, Conselho do Mercado Comum, Grupo do Mercado Comum, Comissão de Comércio, Parlamento do Mercosul e Tribunal Permanente de Revisão. Mas há ainda outros órgãos com competências próprias, a exemplo do Tribunal Administrativo Trabalhista e o Foro Consultivo Econômico e Social ${ }^{24}$.

Embora tenha uma aparência institucional robusta e, de fato, possua uma trajetória antiga de esforços de integração, o modelo intergovernamental do Mercado Comum do Sul ainda precisa amadurecer muito institucionalmente.

\footnotetext{
${ }^{24}$ Cumpre destacar que o Tratado de Assunção trouxe uma estrutura provosória ao MERCOSUL, que era formado pelo Conselho do Mercado Comum (CMC), Grupo do Mercado Comum (GMC), Secretaria Administrativa e Comissão Parlamentar Conjunta. O Protolo de Ouro Preto, manteve alguns órgãos, tornou outros permanentes e ainda estabeleceu outros órgãos ao Mercosul, ficando o bloco estruturado da seguinte forma: CMC, GMC, Comissão de Comércio do Mercosul (CCM); Comissão Parlamentar Conjunta (CPC); Foro Consultivo Econômico-Social (FCES); Secretaria Administrativa do Mercosul (SAM). O Protocolo de Olivos, de 2002, aprimora o sistema de solução de controvérsias criando o Tribunal Permanente de Revisão. E em 2005, com a criação do Parlamento do Mercosul, a CPC, foi substituto pelo novo órgão representante dos cidadãos Mercosulinos. Já a Secretaria Administrativa teve as suas funções e nome modificados pela Decisão CMC 30/02. Maiores informações em: MERCOSUL. Tratado Para a Constituição de um Mercado Comum entre a República Argentina, a República Federativa do Brasil, a República do Paraguai e a República Oriental do Uruguai - Tratado de Assunção, 26 de março de 1991. Disponível em: http://www.mercosur.int/msweb/Normas/Tratado\%20e\%20Protocolos/Tratado\%20Asunci\%C3\%B3n_PT .pdf $>$. Acesso em 10 de dezembro de 2013. MERCOSUL. Protocolo Adicional ao Tratado de Assunção sobre a Estrutura Institucional do MERCOSUL - Protocolo de Ouro Preto, 17 de dezembro de 1994. Disponível em: < http://www.planalto.gov.br/ccivil_03/decreto/D1901.htm>. Acesso em 10 de dezembro de 2013 e MERCOSUL. Conselho do Mercado Comum. Decisão nº 30, 06 de dezembro de 2002. Transformação da Secretária Administrativa do Mercosul em Secretária Técnica. Disponível em: < http://www.mercosur.int/innovaportal/file/74/1/dec_030_002pt.pdf>. Acesso em 10 de dezembro de 2013.
} 
O fato é que, enquanto o Tratado de Lisboa trouxe equilíbrio para o sistema supranacional de competências europeu (conforme se verá adiante), no modelo intergovernamental do Mercosul nem há que se falar em competência e jurisdição (BAPTISTA, 1996, p. 185) . Isso porque o modelo Mercosulino vem sendo conduzido em bases exclusivamente comerciais.

No entanto, a própria natureza dos processos de integração indica que sobre fatos históricos, econômicos e sociais tomam-se decisões políticas. A iniciativa integracionista não escapa a uma construção jurídica que se adéque aos fins comuns dos Estados envolvidos ${ }^{25}$.

Trata-se de conferir ao processo de integração o valor jurídico essencial da segurança jurídica. Isso significa que o ambiente institucional do Mercosul deve estar apto a produzir as normas que incidirão com grande impacto sobre a estrutura produtiva dos Estados Partes.

Definitivamente o Mercosul jurídico se ressente da ausência de uma ordem composta por normas uniformes e obrigatórias para os Estados Partes. Consequentemente, distancia-se de um modelo de integração orientado por regras - rule oriented (TRINDADE, 2007, p. 03).

A opção política pela intergovernabilidade teve como consequência o adiamento do início dos trabalhos de elaboração de um sistema definitivo de composição de divergências. A iniciativa ficou relegada para o final do processo de convergência da Tarifa Externa Comum, a teor do artigo 44 do Protocolo de Ouro Preto.

Na contramão, o sistema de solução de controvérsias, seja no acanhamento do Tratado de Assunção, seja na falta de consistência do Protocolo de Ouro Preto - que apenas reafirma o Protocolo de Brasília -, excluiu os cidadãos das vias de solução de conflitos.

Além da notória timidez face aos assuntos sociais, aliada ao deficit de política democrática desse processo de integração, a livre circulação de trabalhadores tem igualmente correspondido a um dos grandes desafios do projeto fundamental de constituição do Mercado Comum.

É imperioso fomentar a participação da sociedade no processo de integração regional, sobretudo através da difusão da sua dimensão econômica e social. Mas, na prática, grande parte da população do Mercosul ainda não está familiarizada com os efeitos que um projeto de integração desse porte pode provocar no cotidiano do cidadão Mercosulino.

Dificuldades de ordem política e obstáculos gerados pelas assimetrias econômicas de seus Estados Partes explicam em parte esse atraso. Mas a questão pode ser ainda mais profunda, passando pela própria concepção de soberania por parte dos Estados que compõem o bloco.

\subsection{A nova soberania como limite à integração?}

Analisadas as experiências históricas na América do Sul e América Latina com seus resultados práticos contemporâneos, é de se concluir que os Estados membros do Mercosul assimilam de diferentes maneiras a proposta da integração.

\footnotetext{
25 O mecanismo avençado, que continua provisório, elegeu o Estado como o principal sujeito das controvérsias, gerando hiatos ou impondo limitações em vários aspectos. Além disso, insisitu-se na permanência de procedimentos precários e meramente diplomáticos, o que pode comprometer o futuro do modelo, se o mercado comum ainda for a meta dos governos e condutores do processo (D`ANGELIS, 2000. p. 145)!
} 
Quatorze anos se passaram e ainda é atual a conclusão de Celso D. de Albuquerque Mello, para o qual a questão é que "os modos de solução adotados são aqueles que ainda respeitam a noção de soberania que existiu em 1945" (MELLO, 1996, p. 306/307).

E segue afirmando que: "É como se a América Latina não confiasse nela mesma. Não há assim nenhuma Corte de Justiça que preexista e sobreviva ao litígio. Esta ausência acarretará a falta de uma uniformidade na aplicação das normas do Mercosul". (MELLO, 1996, p. 306/307).

A nosso ver, isso tem relação com o significado que o conceito de soberania ainda possui nos quadros do Mercosul, alinhado aos paradigmas clássicos de soberania absoluta da Carta da ONU de 1948.

Conforme ensina Quintão Soares (SOARES, 2004, p. 108), “(...) não se admitia, nos limiares do século XX, que o Estado, no contexto internacional, apesar das obrigações impostas pelo DIP, se submetesse a um poder superior".

Todavia, ao contrário do que se pensa, não há uma contradição entre a soberania dos Estados e os processos de integração (PINTO, 2010, p. 128). Tampouco há que se cogitar desgaste substancial que indique uma crise do Estado ou do conceito de soberania como um todo.

Daí a Teoria da Soberania Partilhada, que, como o próprio nome sugere, explica a transferência das competências estatais mediante um esquema de partilha entre os órgãos supranacionais e os Estados membros.

Os adeptos dessa teoria sustentam que, mediante a assinatura de tratados internacionais, determinados Estados firmaram compromissos de tal modo que a titularidade da soberania passou a ser partilhada entre os Estados e os órgãos supranacionais.

É o que ocorre com os Estados Membros da União Europeia, cujo exercício das competências concorrentes entre Estados membros e União foi definitivamente disciplinado pelo Tratado de Lisboa em dezembro de 2007.

Diferencia-se fundamentalmente de outra teoria, para a qual não se trata de uma questão de partilha da titularidade, e sim de uma verdadeira limitação que se impõe contemporaneamente à própria soberania, no conceito mais clássico.

Segundo a Teoria da Soberania Limitada, fica evidente, sobretudo nos processos de integração, que a própria noção de soberania se modificou. Em razão das transformações mundiais, os Estados já se apresentam sob uma visão cada vez mais limitada de soberania.

Existem nos espaços de integração limites intransponíveis à transferência de competências originárias do Estado para as instituições comunitárias. O Direito é todo ele elaborado e promulgado pelo Estado, o único capaz de lhe emprestar a força coativa necessária para a sua existência.

E, se todo o direito emana do Estado, é de se concluir que o poder político do Estado não reconhece tal limitação, ao contrário, goza de proteção pelas mesmas normas que lhes autorizam nos tratados.

Segundo Dinh e Pellet (DINH; DAILLIER; PELLET, 1999, p. 90), o problema "é que não é fácil conceber que entidades, que se pretendam "acima de tudo soberanas", devam, ou mesmo possam, submeter-se ao direito e vejam a sua liberdade de ação limitada por ele". Mas, o conceito de soberania não é um conceito absoluto.

Assim, o Direito Internacional é, antes de mais nada, um direito aplicável a entidades soberanas e a soberania do Estado não se choca com qualquer outra. Mesmo assim, são os exatos limites que o Direito Internacional impõe aos Estados soberanos 
que os colocam em patamar de igualdade no plano internacional. Daí resulta, inclusive, a sua obrigatoriedade, como fundamento da igualdade soberana entre os Estados.

Dinh, Dailler e Pellet (DINH; DAILLIER; PELLET, 1999, p. 200), lembram que:

\begin{abstract}
Esse princípio da igualdade soberana apresenta-se como o fundamento da cooperação das Nações Unidas no art. $2^{\circ}$, parágrafo $1^{\circ}$ da Carta das Nações Unidas e será desenvolvido, senão explicitado na Declaração relativa aos princípios de direito internacional respeitantes às relações amigáveis e à cooperação dos Estados (resolução 2625 XXV da A.G.)
\end{abstract}

Além dos limites impostos pelo Direito Internacional ao Estado soberano há ainda a questão do conflito entre as normas internacionais e a ordem jurídica interna dos Estados, suscitando debates à luz das teorias dualista e monista.

A primeira foi desenvolvida por Heinrich Triepel $^{26}$ e no Brasil, defendida por nomes como Amilcar de Castro (CASTRO, 2011, p. 249) e Hildebrando Accioly (ACCIOLY; SILVA; CASELA, 2008). Deriva, conforme leciona Fausto de Quadros (PEREIRA; QUADROS, 2007, p. 83-85), do voluntarismo pluriestadual.

Sustenta que não há interseção entre a ordem internacional e a ordem interna, inexistindo assim qualquer possibilidade de conflito entre ambas.

Isso porque, enquanto que as normas de direito internacional disciplinam as relações entre os Estados e entre estes e os demais entes da sociedade internacional, o direito interno rege tão somente as relações intra-estatais, sem conexão com elementos externos.

Segundo os dualistas há profundas diferenças no esquema das fontes, que no Direito Interno é a vontade dos Estados e no Direito Internacional é a vontade de vários Estados. E também quanto aos sujeitos, que no Direito Interno são pessoas singulares e coletivas, e no Direito Internacional são os Estados ${ }^{27}$.

Em sentido contrário caminha o monismo jurídico, desenvolvido pela escola austríaca de Hans Kelsen e adotada pela maioria da doutrina brasileira, a exemplo de Valerio de Oliveira Mazzuoli (MAZZUOLI, 2009, p. 75) e Celso D. Albuquerque Mello (MELLO, 1996, p. 50).

O monismo assevera que o direito constitui uma unidade, um sistema integrado, ao mesmo tempo, por normas de direito internacional e normas de direito interno.

Nesse sentido, podem preponderar ou a ordem internacional - denominado monismo com primazia do Direito Internacional (ou monismo internacionalista), ou a ordem interna - monismo com primazia do direito interno (ou monismo nacionalista).

A tese monista com primazia do Direito interno não é mais do que a negação do Direito Internacional, absorvido pelo direito nacional. Resulta do voluntarismo uni-estatal, que tem como expoentes Zorn, Wenzel e Jellinek.

O monismo de Direito Internacional, por outro lado, resulta da rejeição ao voluntarismo e é a concepção preponderante nos dias de hoje, tida doutrinariamente

\footnotetext{
${ }^{26}$ Segundo a teoria da incorporação de Triepel do fim do século XIX, uma norma internacional somente se aplica no âmbito interno dos Estados quando se transforma em Direito Interno. Dessa forma, os tribunais do ordenamento jurídico interno só aplicam a legislação interna que põe em vigor o tratado, e não o próprio tratado. Tal concepção, apesar de ultrapassada, ainda é adotada por alguns Estados. Cf. TRIEPEL, H. 1925. No Brasil, SILVA, 2008, p. 156.

27 Fausto de Quadros ressalta que a doutrina foi acolhida pelo Tribunal Permanente de Justiça Internacional no caso Chorzow, com vários e sucessivos acórdão proferidos nesse sentido: $25-5-25$, in Série A, $n^{\circ} 6$; 26-7-27, in Série A, nº 9; 16-12-27, in série A, $n^{\circ} 13$; 13-9-28, in Série A, $n^{\circ} 17$ (PEREIRA; QUADROS, 2007, p. 84).
} 
como aquela consentânea ao estado atual das relações jurídicas na Comunidade Internacional (PEREIRA; QUADROS, 2007, p. 83-85).

Nos quadros do regime europeu de partilha de poder, questão relevante diz respeito à reversibilidade das competências partilhadas entre a União e os Estados Membros.

A questão está atrelada a outra, relativa à origem das competências comunitárias, no que tange à qualificação do ato voluntário expresso dos Estados membros que conferiu tais competências inicialmente à Comunidade, e, em seguida, à União.

Aqui, duas posturas colimam ideias distintas.

A primeira sustenta que os Estados membros efetivamente transferiram para a Comunidade parcelas da sua soberania, tendo como consequência a perda de todo e qualquer poder de intervenção em favor da União, que passaria a ostentar competência exclusiva dali em diante.

Por outro lado, outros defendem que a transferência ocorreria tão somente na esfera do exercício das competências, jamais da titularidade. Segundo esse entender, haveria tão somente a mera delegação de poderes dos Estados à Comunidade (QUADROS, 2004, p. 100).

Nesse mister faz-se necessário mencionar decisão do Tribunal de Justiça no famoso acórdão COSTA/ENEL de 31 de março de 1971, que referiu-se à Comunidade como uma entidade "dotada de poderes reais resultantes de uma limitação de competência ou de uma transferência de atribuições dos Estados para a Comunidade (...)" (VILHENA, 2002, p. 103)

Vilhena (VILHENA, 2002, p. 103) observa que nesse caso parece haver uma tendência para a tese da transferência de competências, cuja definitividade parece reforçada pela afirmação de que

a transferência efetuada pelos Estados membros, da sua ordem jurídica interna em proveito da ordem jurídica comunitária, de direitos e obrigações correspondentes às disposições do tratado, envolve, pois, uma limitação definitiva dos seus poderes soberanos (...).

Mas a controvérsia fica evidente quando o Tribunal dispõe no mesmo acordão que:

\begin{abstract}
Os Estados membros acordaram em instituir uma Comunidade de duração ilimitada, dotada de órgãos permanentes investidos de poderes reais, resultantes de uma limitação de competência ou de uma transferência de atribuições dos Estados a esta Comunidade; (...) a perda [pela Comunidade] das competências assim conferidas e o regresso das matérias abrangidas ao domínio da competência exclusiva dos Estados membros só se poderia verificar em virtude de uma disposição expressa do tratado.
\end{abstract}

Contrario sensu à corrente da transferência, a leitura dessa parte do julgado indica a possibilidade de que a reversão dos poderes concedidos pelos Estados Partes estaria adstrita à sua expressa disposição no texto do Tratado, prevalecendo a ideia de delegação.

Assim, parece-nos cediço - sobretudo com os novos contornos do sistema de atribuição de competências da União Europeia ratificado pelo Tratado de Lisboa que, se apenas o próprio Estado é quem pode transferir parcela de sua soberania, então é perfeitamente legítimo imaginar que ele próprio possa reverter tal concessão, se assim o desejar. Daí, esse limite aparecer expressamente no texto dos tratados de cooperação. 
Atualmente, após o Tratado de Lisboa que regulamentou definitivamente as competências, conforme o princípio da subsidiariedade, restaram superadas as eventuais controvérsias a respeito o sistema europeu de atribuição de competências.

\section{CONSIDERAÇÕES FINAIS}

Podemos afirmar que o mundo se depara com uma terceira versão de regionalismo, que vem na sequência daquela segunda tendência, pós-Segunda Guerra Mundial, responsável pela formação dos primeiros blocos regionais.

A comunidade internacional, que outrora teve a construção europeia como inspiração para o nascimento sequencial de novos projetos de integração, hoje assiste ao exemplo europeu com mais ponderação. Por ali, os problemas enfrentados conjuntamente pelos Estados suscitam diversos questionamentos a respeito das consequências do aprofundamento das relações entre os Estados.

É tarefa complexa apontar exatamente onde estão os principais focos da crise, bem como pode ser precipitado atribuir à integração a culpa por todas as mazelas contemporâneas.

É preciso também enaltecer o fortalecimento da capacidade individual de superação cada Estado na União Europeia, e reconhecer-lhe méritos, sem recorrer para a tendência reacionária do retrocesso.

Caso contrário, seria negar uma série de conquistas e avanços, a exemplo do que se deu no que se refere aos sistemas regionais de proteção aos direitos do homem.

O cidadão europeu que outrora estava entregue exclusivamente ao inepto e problemático sistema global da ONU, passou a acumular proteção própria, conferida num quadro institucional-normativo de referência na questão da proteção internacional dos direitos do homem.

Funcionando em coexistência com o sistema da ONU - a inspiração da Declaração Universal dos Direitos Humanos e a proteção do Pacto Internacional de Direitos Civis e Políticos e do Pacto Internacional de Direitos Econômicos, Sociais e Culturais - as etapas da União Europeia conduziram ao mais completo e respeitado modelo contemporâneo de proteção aos Direitos Humanos.

Além da Convenção Europeia dos Direitos do $\mathrm{Homem}^{28}$ e da Carta dos Direitos Fundamentais da União Europeia ${ }^{29}$, o sistema europeu ainda conta com a e da existência de um tribunal próprio para os litígios que digam respeito aos Direitos do Homem $^{30}$.

A lição que a crise pode ter trazido é a de que não há que se pregar a simples imitação do projeto de integração como estratégia de salvação dos Estados endividados. Inclusive porque um período de crise sempre exigirá uma política nacional de austeridade e um esforço individual de responsabilidade dos Estados, sem o qual nenhuma solução se afigurará viável.

\footnotetext{
${ }^{28}$ Firmada no âmbito do Conselho da Europa desde 1950, a Convenção Europeia dos Direitos do Homem é o principal diploma internacional no sistema europeu de proteção aos direitos do homem. Anterior à União Europeia, o Conselho da Europa constitui organização internacional com notória vocação para a defesa dos Direitos Humanos, tendo participado historicamente nas profundas modificações havidas desde o pós-guerra, desempenhando a função de exigir dos Estados europeus a adoção de elevados padrões de defesa dos Direitos Humanos.

${ }_{29}$ Proclamada solenemente em dezembro de 2000, na cidade de Nice, França, a Carta dos Direitos Fundamentais da União Europeia é dotada de cinquenta e quatro artigos repartidos por sete capítulos: Dignidade; Liberdade; Igualdade; Solidariedade; Cidadania; Justiça; e Disposições Gerais.

${ }^{30}$ Vale dizer, o Tribunal Europeu dos Direitos do Homem não constitui propriamente um órgão da União Europeia, funcionando como uma jurisdição do Conselho da Europa.
} 
As iniciativas de integração são válidas, uma vez que, ao se agruparem, os países conseguem alavancar as suas economias, permitindo abertura de mercado, especialmente com a eliminação de barreiras comerciais e alfandegárias.

Ao que parece, a América do Sul já demonstrou essa intenção através dos doze países que compõem a UNASUL, sinalizando ações coordenadas para enfrentar a nova etapa da crise financeira internacional.

Entre as principais medidas, destacam-se o comércio intra-bloco e a criação de um fundo financeiro.

Os países da América do Sul planejam ainda adotar medidas para reforçar o comércio regional em moedas locais, impondo restrições ao dólar. $\mathrm{O}$ intuito é proteger as reservas e incrementar o comércio entre os países da região, que atualmente equivale a cerca de US\$ 120 bilhões por ano.

Para que se renovem as esperanças quanto ao futuro da integração da América do Sul, é imperativo que se proceda, primeiro, uma revisão do paradigma de soberania no bloco. Impõe-se uma reconstrução ideológica do Estado, conjugando-se os ideais de Simón Bolívar com os desafios que atualmente se impõe aos Estados Mercosulinos e à comunidade internacional como um todo.

O momento é, portanto, de avançar e não de retrair-se. Perante a crise, cada vez mais se impõe que as iniciativas de integração deixem de ser vistas com desconfiança pelos Estados envolvidos. Em tempos de crise, o receio histórico que sempre limitou América do Sul e América Latina deve ser visto como uma reverência leviana ao regresso.

Contrario sensu, é preciso resgatar-se no espírito bolivariano a vocação histórica dos Estados da América do Sul como alternativa de superação dos problemas regionais. Recorrer à estratégia integracionista nada mais é do que adotar iniciativas coletivas para problemas comuns.

Ora, se construções como o Mercosul e a UNASUL podem, por um lado, significar uma redenção para os Estados menos desenvolvidos, para as economias mais fortes a integração tem se demonstrado um recurso extremamente útil e bem sucedido na superação das adversidades globais.

Primeiro, porque não implica perda de autonomia nem de poderes exclusivos por parte do Estado, mas sim uma cessão voluntária. Conforme se apontou, até mesmo no modelo supranacional europeu é possível a cláusula de reversibilidade das competências, embora adstrita à expressa disposição no texto dos Tratados.

Além disso, o procedimento também pode ser revisto caso a possibilidade de retirada esteja prevista no Tratado de integração e à medida que não mais interessar ao Estado participar daquele processo de integração.

E, ao tempo em que se afirma a cessão de soberania dos Estados nos domínios comerciais e ambientais, por exemplo, o poder exclusivo do Estado continua a ser exercido nos limites de seu território. Parece modificada - isso sim - a ideia do Estado provedor, embora se conserve soberana a respectiva ordem constitucional.

\section{REFERÊNCIAS}

ACCIOLY, Hildebrando; SILVA, G.E. do Nascimento; CASELLA, Paulo Borba. Manual de Direito Internacional Público. 16. ed. reformul. São Paulo: Editora Saraiva, 2008. 
ARNAUD, Vicente Guillhermo. MERCOSUR, Unión Europea, Nafta Y Los Procesos de Integración Regional. 2. ed. ampl. y atual. Buenos Aires: Abeledo-Perrot, 1999.

BALASSA, Bela. The theory of economic integration. trad. Clássica editor. Londres: George Allen e Unwin, 1961.

BAPTISTA, Luis Olavo. O Mercosul Após o Protocolo de Ouro Preto. Estudos Avançados. Vol. 10, n .27. São Paulo, 1996.

CASTRO, Amilcar de. Direito Internacional privado. 5. ed. aum. e atual. Rio de Janeiro: Forense, 2001.

D`ANGELIS, Wagner Rocha. Mercosul: da Intergovernamentalidade à Supranacionalidade? Perspectivas jurídicas para a Efetivação do Mercado Comum. Curitiba: Editora Juruá, 2000.

DINH, Nguyen Quoc; DAILLIER, Patrick Daillier; PELLET, Alain. Direito internacional público. trad. Vítor Marques Coelho. 2. ed. Lisboa: Fundação Calouste Gulbenkian, 1999.

DUARTE, Maria Luísa. Direito da União Europeia e das Comunidades Europeias. Lisboa: Lex, 2001.

FERREIRA, Graça Enes. A Teoria da integração econômica internacional e o modelo de integração do espaço econômico europeu. Porto: Legis Editora, 1997.

GONZALES, A. C. 1979. Reflexiones Sobre el Futuro de la ALALC Integración Latinoamericana: El Futuro de la ALALC, Revista Mensal do INTAL no. 40 In: PINTO, Hugo Eduardo Meza e BRAGA, Márcio Bobik. A lógica do Regionalismo na América Latina e a Comunidade Andina das Nações. Disponível em <https:// www.usp.br/prolam/downloads/versao3.doc>. Acesso em 04 de abril de 2013.

MAZZUOLI, Valerio de Oliveira. Curso de Direito Internacional Público. 3. ed. São Paulo: Editora RT, 2009.

MERCOSUL. Tratado Para a Constituição de um Mercado Comum entre a República Argentina, a República Federativa do Brasil, a República do Paraguai e a República Oriental do Uruguai - Tratado de Assunção, 26 de março de 1991. Disponível em: < http://www.mercosur.int/msweb/Normas/Tratado\%20e\%20Protocolos/Tratado\%20Asu nci\%C3\%B3n_PT.pdf >. Acesso em 10 de dezembro de 2013.

MERCOSUL. Protocolo Adicional ao Tratado de Assunção sobre a Estrutura Institucional do MERCOSUL - Protocolo de Ouro Preto, 17 de dezembro de 1994. Disponível em: < http://www.planalto.gov.br/ccivil_03/decreto/D1901.htm>. Acesso em 10 de dezembro de 2013.

MERCOSUL. Conselho do Mercado Comum. Decisão n 30, 06 de dezembro de 2002. Transformação da Secretária Administrativa do Mercosul em Secretária Técnica. 
Disponível em: < http://www.mercosur.int/innovaportal/file/74/1/dec_030_002pt.pdf>. Acesso em 10 de dezembro de 2013.

MELLO, Celso de Albuquerque. Direito Internacional de Integração. Rio de Janeiro: Renovar, 1996.

MUNOZ, Juan Carlos Duenas. Soberania y Estado Constitucional: Su importancia en la Integración y en EI Derecho Comunitario. Disponível em:

<https://www.juridicas.unam.mx>. Acesso em 05 de maio de 2013.

NOGUERAS, Diego J. Liñan; MARTÍN, Araceli Mangas. Instituciones y derecho de la unión europea. Madrid: Tecnos, 2002.

OCAMPO, Raúl Granillo. Direito Internacional Público da Integração. Trad. Sérgio Duarte. Rio de Janeiro: Campus Jurídico/Elsevier, 2009.

PEREIRA, André Gonçalves e QUADROS, Fausto de. Manual de direito internacional público. 3. ed. Coimbra: Almedina, 2007.

PINTO, Mendonça. União monetária europeia. Lisboa: Universidade Católica Editora, 1995.

PINTO, Marcio Morena. La Dimensión de La Soberanía En EI Mercosur. Curitiba: Juruá Editora, 2010.

QUADROS, FAUSTO de. O Modelo Europeu. Revista Conselho da Justiça Federal, número 2, agosto/1997. Disponível em:

<https://www.cjf.jus.br/revista/numero2/artigo2.htm>. Acesso em 02 de março de 2013.

QUADROS, Fausto de. Direito da União Europeia. Coimbra: Almedina, 2004.

QUINTÃO SOARES, Mário Lúcio. Teoria do Estado. 2. Ed. rev. Atual. Belo Horizonte: Del Rey, 2004.

SILVA, Roberto Luiz. Direito Internacional Público. 3. ed. Belo Horizonte: Editora Del Rey, 2008.

TRINDADE, Otávio A. D. Cançado. O Mercosul no Direito Brasileiro. Incorporação de normas e Segurança Jurídica. Belo Horizonte: Editora Del Rey, 2007.

TRIEPEL, H. Les Rapports entre le Droit Interne et le Droit International. Recueil de Cours de L'Academy de Droit International, tomo I, 1925.

VILHENA, Maria do Rosário. O Princípio da Subsidiariedade no Direito

Comunitário. Coimbra: Almedina, 2002.

Dicionário de Termos Europeus. Lisboa: Alêtheia Editores, 2005. 